\title{
Polarization reversal via a transient relaxor state in nonergodic relaxors near freezing temperature
}

\author{
Chang-Hyo Hong a , Hanzheng Guo ${ }^{\text {b }}$, Xiaoli Tan ${ }^{\text {b }}$, John E. Daniels ${ }^{\text {c }}$, Wook Jo ${ }^{\text {a, * }}$ \\ a School of Materials Science and Engineering, Ulsan National Institute of Science and Technology, Ulsan, 44919, Republic of Korea \\ b Department of Materials Science and Engineering, Iowa State University, Ames, IA, 50011, USA \\ ' School of Materials Science and Engineering, University of New South Wales, New South Wales, 2052, Australia
}

\section{A R T I C L E I N F O}

\section{Article history:}

Received 18 April 2019

Received in revised form

7 June 2019

Accepted 24 June 2019

Available online 25 June 2019

\section{Keywords}

Relaxor

Nanodomains

In situ

Neutron diffraction

Transmission electron microscopy

\begin{abstract}
A B S T R A C T
Among the unresolved issues in the study of relaxor ferroelectrics is the role of freezing temperature, across which the dynamics of polarization reversal in relaxor ferroelectrics changes. The presence of this freezing temperature is best manifested by the appearance of a double polarization hysteresis loop just above the freezing temperature. Given that the polarization pinching evolving into a double hysteresis starts well below the freezing temperature, there exists a transient temperature regime between the nonergodic and the ergodic relaxor states. To clarify the role of the freezing temperature on the pinching, the polarization reversal near the freezing temperature of relaxor $\left(\mathrm{Pb}_{1-x} \mathrm{La}_{x}\right)\left(\mathrm{Zr}_{1-y} \mathrm{~T}_{y}\right)_{1-x / 4} \mathrm{O}_{3}$ (PLZT) was monitored using three in situ electric field methods: electrocaloric effect, neutron diffraction, and transmission electron microscopy. We demonstrate that the pinching results from a two-step process, 1) domain detexturization in the ferroelectric state and 2) miniaturization of domains. This observation explains the recently reported gap between the depolarization temperature $T_{\mathrm{d}}$ and the ferroelectric-torelaxor transition temperature $T_{\mathrm{F}-\mathrm{R}}$ in lead-free relaxors. We further show that $T_{\mathrm{d}}$ and $T_{\mathrm{F}-\mathrm{R}}$, which have long been considered identical in lead-based relaxors, are not the same. The current study suggests that the mismatch between $T_{\mathrm{d}}$ and $T_{\mathrm{F}-\mathrm{R}}$ is an inherent feature in both lead-based and lead-free relaxor ferroelectrics.
\end{abstract}

(c) 2019 The Chinese Ceramic Society. Production and hosting by Elsevier B.V. This is an open access article under the CC BY-NC-ND license (http://creativecommons.org/licenses/by-nc-nd/4.0/).

\section{Introduction}

Relaxor ferroelectrics have been studied extensively due to their use in a versatile applications and also due to their intriguing physical phenomena that are yet to be clarified [1-3]. Among such intriguing phenomena is the existence of Vogel-Fulcher temperature $\left(T_{\mathrm{VF}}\right)$, commonly referred to as the freezing temperature $\left(T_{f}\right)$ [4-7]. Below $T_{f}$, the longest relaxation time of polar nanoregions (PNRs) diverges [8]. A relaxor below $T_{f}$ is called a nonergodic relaxor, while that above $T_{f}$ is an ergodic relaxor [9]. Due to the dynamics of PNRs, a permanent long-range ferroelectric order can be induced in nonergodic relaxors with the application of an external electric field. Once this long-range ferroelectric order is induced, nonergodic relaxors are indistinguishable from normal ferroelectrics with respect to their functional properties such as

\footnotetext{
* Corresponding author.

E-mail address: wookjo@unist.ac.kr (W. Jo).

Peer review under responsibility of The Chinese Ceramic Society.
}

polarization and strain hysteresis. This electric-field-induced ferroelectric state in nonergodic relaxors is disturbed when they are heated up above the ferroelectric-to-relaxor transition temperature $\left(T_{\mathrm{F}-\mathrm{R}}\right)$, where they transform into ergodic relaxors.

It is commonly known that this transition back to an ergodic relaxor state is accompanied by the appearance of an anomaly in both the real and the imaginary part of the dielectric permittivity [10]. Meanwhile, an electric field applied to a nonergodic relaxor induces a ferroelectric state and hence piezoelectricity. Therefore, from the piezoelectric point of view, a so-called depolarization temperature $\left(T_{\mathrm{d}}\right)$, commonly determined by thermally-stimulated depolarization current (TSDC) measurement [11,12], is of practical importance, as it marks the upper temperature limit for piezoelectric applications. On the other hand, the presence of $T_{\mathrm{d}}$ is also well-reflected in the thermal evolution of polarization hysteresis loops. As the temperature is increased to near $T_{f}$, the polarization hysteresis loop of nonergodic relaxors starts to be pinched, resulting in a double-loop polarization hysteresis. The appearance of double-loop polarization hysteresis is not unique in relaxor systems since the double-loop polarization hysteresis merely 
requires a macroscopic paraelectric state at zero field [13]. It is noted that the pinched hysteresis loop near $T_{\mathrm{f}}$ is different from the double hysteresis loop of defect-induced relaxors [14,15], which usually de-pinches after successive electrical cycling [16-18]. The pinched hysteresis of relaxors implies that near $T_{f}$, the polarization reversal takes place in two steps, i.e., the polarization reversal involves a transient macroscopic relaxor state [19]. In principle, the depoling electric field $E_{\mathrm{d}}$, where the induced polarization starts to vanish during unloading electric field (See, for example, Fig. 1 for the meaning of notations used in the current work) reaches $0 \mathrm{kV} /$ $\mathrm{mm}$ at $T_{\mathrm{d}}$.

So far, in canonical relaxors such as $\mathrm{Pb}\left(\mathrm{Mg}_{1 / 3} \mathrm{Nb}_{2 / 3}\right) \mathrm{O}_{3}$ (PMN) [20-22] and $\left(\mathrm{Pb}_{1-x} \mathrm{La}_{x}\right)\left(\mathrm{Zr}_{1-y} \mathrm{~T}_{y}\right)_{1-x / 4} \mathrm{O}_{3}$ (PLZT) $[13,23,24], T_{f}, T_{\mathrm{d}}$, and $T_{\mathrm{F}-\mathrm{R}}$ have been considered to be the same. However, a number of recent experimental works on lead-free compositions suggest that $T_{\mathrm{F}-\mathrm{R}}$ does not have to be identical with $T_{\mathrm{d}}[19,25,26]$. It implies that the depolarization and the transition to the ergodic relaxor state of electrically-induced ferroelectric state are separate processes. In fact, it was demonstrated in $0.94\left(\mathrm{Bi}_{1 / 2} \mathrm{Na}_{1 / 2}\right) \mathrm{TiO}_{3}-0.06 \mathrm{BaTiO}_{3}$ (94BNT-6BT) that the process taking place across $T_{\mathrm{d}}$ and then $T_{\mathrm{F}-\mathrm{R}}$ is a detexturization of electrically aligned ferroelectric domains, followed by the miniaturization of the detexturized ferroelectric domains with a long-range order $[13,19,25]$. This means that the thermal energy required for depolarizing the electrically textured state is smaller than that for disrupting electrically-induced longrange ferroelectric order. As aforementioned, these stepwise processes are absent in normal ferroelectrics [27,28]. Given this, the polarization reversal near $T_{\mathrm{d}}$ should, in fact, occur in three steps: 1 ) poled state decays into randomly oriented domains, 2) detexturized ferroelectric state breaks down to macroscopic relaxor state, 3 ) textured ferroelectric state aligned in the opposite direction is manifested [29]. Here, we demonstrate that the polarization reversal near $T_{\mathrm{d}}$, indeed, takes place in three steps, using calorimetry, neutron diffraction, and transmission electron microscopy.

\section{Experimental}

Hot-pressed commercially available PLZT8/65/35 (Boston Applied Technologies, MA, USA) was used for this study. For
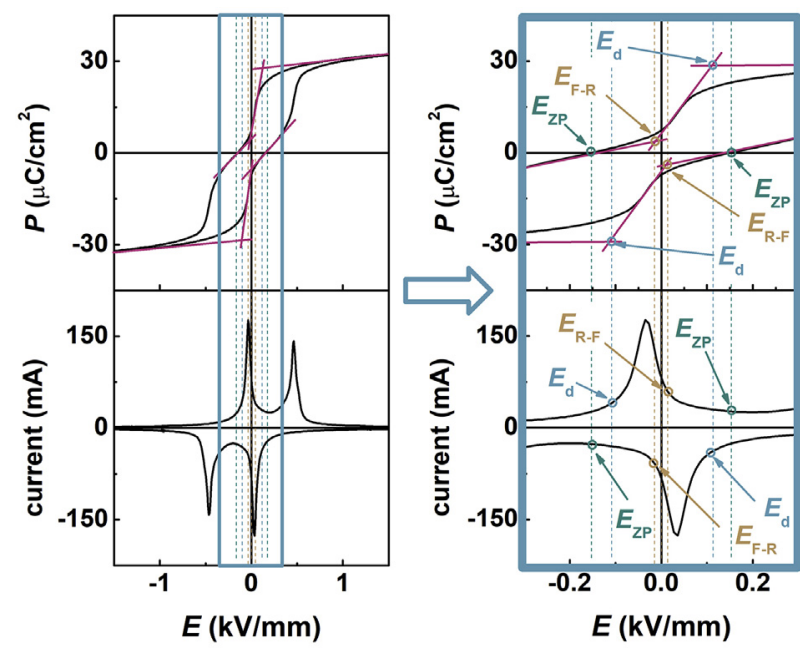

Fig. 1. Intersections of linear extrapolation lines of saturated polarization and pinched polarization curves were used to specify the stepwise polarization reversal process via a ferroelectric-to-relaxor state. Notation $E_{\mathrm{d}}, E_{\mathrm{F}-\mathrm{R}}$, and $E_{\mathrm{R}-\mathrm{F}}$ denote depoling electric field, transition electric field from the ferroelectric-to-relaxor state, and relaxor-toferroelectric state, respectively. The zero polarization electric field $E_{\mathrm{ZP}}$ is used instead of the coercive field $E_{\mathrm{C}}$ where depolarization takes place in typical ferroelectrics. comparison purpose, a commercial soft PZT (PIC 151, PI Ceramic, Lederhose, Germany) and self-made $0.94\left(\mathrm{Bi}_{1 / 2} \mathrm{Na}_{1 / 2}\right) \mathrm{TiO}_{3}-$ $0.06 \mathrm{BaTiO}_{3}$ (BNT-6BT) [30] were also utilized.

Electrocaloric effects were quantified by a direct measurement method using a homemade in situ calorimeter which consists of a vacuum bottle, silicone oil, and a temperature sensor (Pt 100, Heraeus Sensor Technology GmbH, Germany). The temperature sensor was directly attached to the sample surface. The triangular bi-polar electric field was applied at $0.1 \mathrm{~Hz}$ by a power supply (20/ 20C, Trek, Inc. USA). Polarization hysteresis and switching current loops were obtained with a piezoelectric evaluation system (aixPES, AixACCT, Germany).

Neutron diffraction experiments were carried out using the Wombat powder diffractometer at the Australian Nuclear Science and Technology Organisations OPAL research reactor. A neutron wavelength of $2.41 \AA$ was used. A detailed description of the experimental geometry is available in Ref. [31]. As there may be some time-dependence to the switching behavior observed in PLZT, we performed time-resolved investigations using a stroboscopic technique. We applied a triangular waveform at $0.1 \mathrm{~Hz}$ where the detected neutrons are sampled into time bins associated with the field at an instantaneous point in time. The data collection combines the sum of many cycles of the waveform. The maximum applied field was $700 \mathrm{~V} / \mathrm{mm}$ for the sample at $23^{\circ} \mathrm{C}$ (room temperature) and $500 \mathrm{~V} / \mathrm{mm}$ for the sample at $40^{\circ} \mathrm{C}$ (above $T_{\mathrm{F}-\mathrm{R}}$ ).

For in situ electric field transmission electron microscopy (TEM), disk specimens were prepared through standard procedures including grinding, cutting, dimpling, and ion milling. The dimpled disks were annealed at $200{ }^{\circ} \mathrm{C}$ for $2 \mathrm{~h}$ to minimize the stressinduced effects prior to Ar-ion milling to electron transparency. In situ TEM experiments were carried out on a specimen that was crack-free at the edge of the central perforation on a Phillips CM30 microscope operated at $200 \mathrm{kV}$. Experimental details can be found in Refs. [32-34].

\section{Results and discussion}

\subsection{Electrocaloric effect}

Polarization hysteresis, switching current, and electrocaloric effect of a commercial PZT (PIC 151, PI Ceramic, Lederhose, Germany) and PLZT ceramics during electrical cycling at room temperature are compared in Fig. 2. For both PIC 151 and PLZT, the initial increase in the polarization value is due to the formation of a textured long-range order induced by the application of the external electric field, accompanied by electrocaloric heating. During a reverse cycle, PIC 151 reveals typical ferroelectric polarization switching with a single switching current, while two discrete peaks are noted in the switching current for PLZT. It is obvious from the temperature change that the first peak, making the polarization state vanished, is related to the transition of the electric-field-induced ferroelectric state back to the original relaxor state [19,35], and the second one stems from the establishment of a textured long-range order along the reverse direction. It is noted that the adiabatic cooling comes from the electromechanical work, devoting to the disruption of the poled state of the electric-fieldinduced ferroelectric phase [36-38].

\subsection{Neutron diffraction}

The structure of as-sintered PLZT is observed to be near cubic using neutron diffraction without any discerned peak splitting nor superlattice reflections (Fig. 3), which is typical for relaxor ferroelectrics [39-43]. As will be shown later, the TEM study confirmed that at a local scale, the initial state of the material is a 

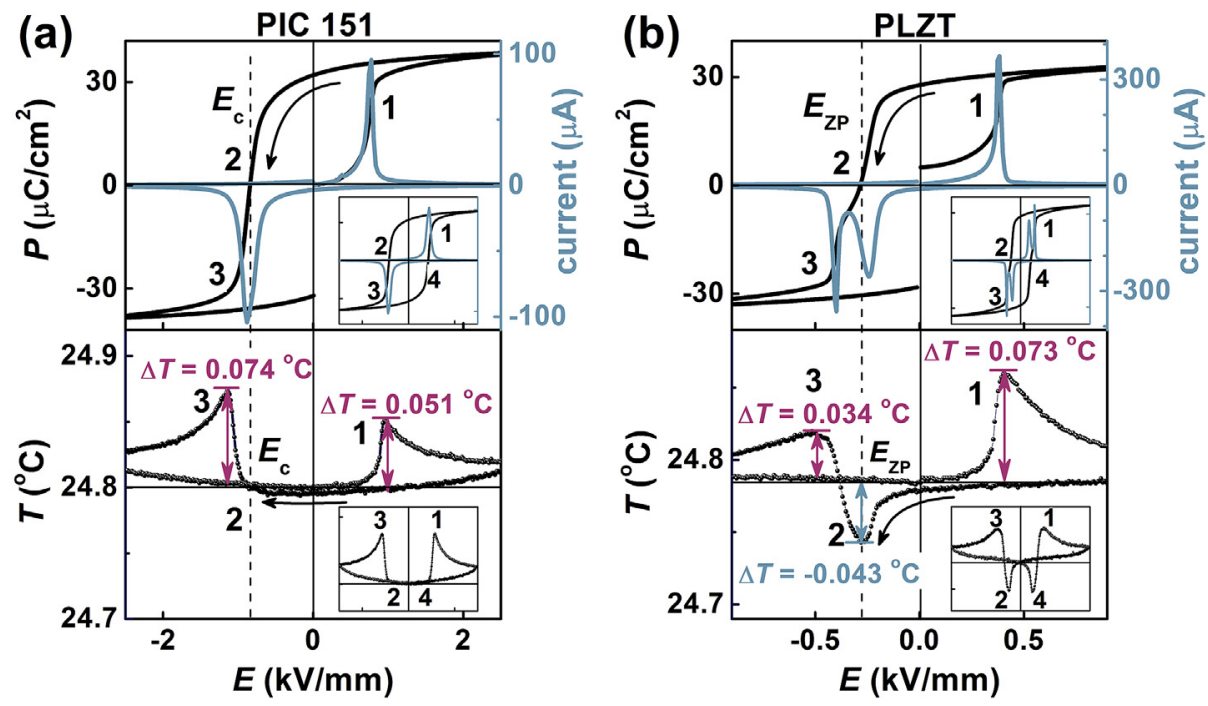

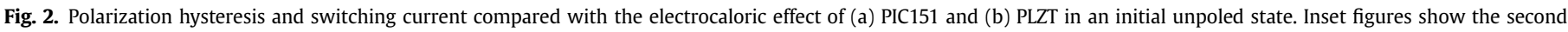
cycle.

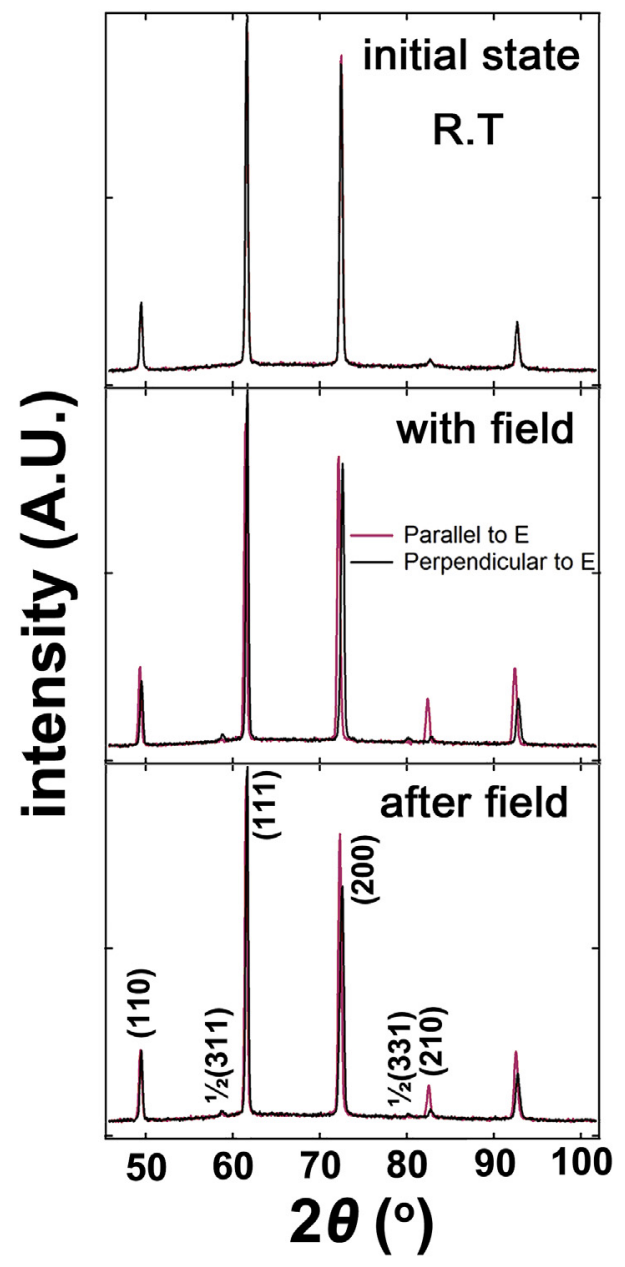

Fig. 3. Change in structure by electrical poling from the unpoled state at $23^{\circ} \mathrm{C}$ and maximum field of $2 \mathrm{kV} / \mathrm{mm}$.

rhombohedral $R 3 m$. It is reasonable to assume that the correlation length of the initially existing oxygen octahedral tilts manifested by superlattice reflections is below the detection limit of the currently utilized neutron diffraction technique; albeit, detectable through a selected area electron diffraction (SAED) as will be presented later.

The application of electric fields at room temperature leads to the development of a significant lattice strain and the appearance of $1 / 2(311)$ and $1 / 2(331)$ superlattice reflections when the scattering vector is aligned along the electric field direction. The appearance of superlattice reflections is most likely associated with an antiphase oxygen octahedral tilting $\left(a^{-} a^{-} a^{-}\right)$. As presented in Fig. 4, the observed change in the diffraction pattern, e.g., an increase in the intensity of (210) with the appearance of $1 / 2(000)$ type superlattice reflections is best-explained, when the initial and the electric-field-induced phase are a macroscopically rhombohedral $R 3 m$ and $R 3 c$, respectively. Note that this does not necessarily mean that the entire material underwent this phase transformation. All grains within the polycrystal are aligned at different orientations to the electric field, and thus can be in different states under the field. The induced superlattice reflections along the field direction do not vanish after the removal of electric field, demonstrating that the electric-field-induced structural changes in this PLZT sample are irreversible at room temperature.

The (210) intensity as a function of applied electric field at $23^{\circ} \mathrm{C}$ (room temperature) and $40^{\circ} \mathrm{C}$ (above $T_{\mathrm{F}-\mathrm{R}}$ ) are presented in Fig. 5 (a) and (b) respectively. The (210) intensity at $23^{\circ} \mathrm{C}$ features the typical ferroelectric strain curve. At $40^{\circ} \mathrm{C}$, the shape changes to a sprout-shaped strain curve with little remnant strain in the lattice, which is commonly observed in ergodic relaxors. It is noticed that there exists a strong correlation between the intensity of $1 / 2(311)$ and (210) reflections and the strain behavior. The intensity of both reflections starts to decrease near $E_{\mathrm{d}}$ and becomes the minimum near $E_{\mathrm{F}-\mathrm{R}}$.

\subsection{Transmission electron microscopy}

Using an in situ TEM technique, the electric-field-induced phase transitions are directly imaged and displayed in Fig. 6 on a representative grain along its $<112>$-zone axis. It is noted that the central perforation in the TEM specimen distorts the electric field [33,34]. As depicted in Fig. 6 (a), at virgin state, it consists of typical polar nanodomains. The corresponding SAED pattern [Fig. 6 (b)] reveals the presence of very weak $1 / 2\{000\}$ superlattice diffraction spots ( $O$ stands for odd Miller indices), which supports our designation of 
Table 1

Fullprof simulation parameter for $R 3 m$ and $R 3 c$.

\begin{tabular}{|c|c|c|c|c|c|c|c|c|}
\hline & & & & $x$ & $y$ & & & Occ. \\
\hline \multirow[t]{5}{*}{$R 3 m$} & & $\mathrm{~Pb}$ & & 0 & 0 & & & 0.5 \\
\hline & & $\mathrm{La}$ & & 0 & 0 & & & 0.5 \\
\hline & & $\mathrm{Zr}$ & & 0 & 0 & & & 0.5 \\
\hline & & $\mathrm{Ti}$ & & 0 & 0 & & & 0.5 \\
\hline & & $\mathrm{O}$ & & 0.16667 & 0.33333 & & & 2.4 \\
\hline \multirow[t]{6}{*}{$R 3 c$} & & $\mathrm{~Pb}$ & & 0 & 0 & & & 0.5 \\
\hline & & $\mathrm{La}$ & & 0 & 0 & & & 0.5 \\
\hline & & $\mathrm{Zr}$ & & 0 & 0 & & & 0.5 \\
\hline & & $\mathrm{Ti}$ & & 0 & 0 & & & 0.5 \\
\hline & & 0 & & 0.12 & 0.78667 & & & 2.4 \\
\hline & $\lambda(\AA)$ & & $a(\AA)$ & $b(\AA)$ & $c(\AA)$ & $\alpha\left({ }^{\mathrm{o}}\right)$ & $\beta\left({ }^{\circ}\right)$ & $\gamma\left({ }^{\circ}\right)$ \\
\hline$R 3 m$ & 2.41 & & 5.77473 & 5.77473 & 7.08165 & 90 & 90 & 120 \\
\hline$R 3 c$ & 2.41 & & 5.77473 & 5.77473 & 14.15724 & 90 & 90 & 120 \\
\hline
\end{tabular}

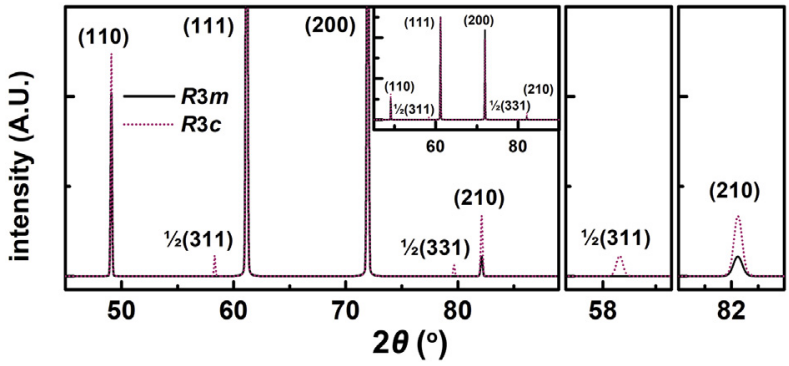

Fig. 4. Comparison of the neutron diffraction pattern simulation between $R 3 m$ and $R 3 C$ (Parameters used in the simulation are presented in Table 1).

$R 3 c$ instead of $R 3 m$ to as-sintered PLZT. Close-up examination of the portion of the SAED pattern for the fundamental diffraction $(\overline{22} 2)$ and the superlattice diffraction spot $1 / 2(\overline{33} 3)$ is displayed in Fig. 6 (c). The $(\overline{22} 2)$ spot features a circular shape, while the $1 / 2(\overline{33} 3)$ superlattice spot is weak and diffuse.

Electric fields with increasing magnitude were applied along the direction indicated by the bright arrow in Fig. 6 (d). At a field corresponding to point ' $\mathrm{d}$ ' in Fig. $6(\mathrm{~m})$, the nanodomains begin to coalesce and cluster in the upper right region of the grain, and transform into long and thin domains on the left as well as lower part of the grain [Fig. 6 (d)]. Compared with the crystallographic orientations revealed in the SAED in Fig. 6 (b), these domains are likely to have their walls on the (110) plane. With further increased electric field up to the field corresponding to point 'e' in Fig. 6 (m) [Fig. 6 (e)], the long and thin domains become broader and wedgeshaped, occupying most part of the grain. The domain walls remain roughly along the same $(\overline{1} 10)$ plane. Fig. $6(\mathrm{a}), 6(\mathrm{~d})$, and $6(\mathrm{e})$ reveal the electric-field-induced relaxor-to-ferroelectric phase transition process in PLZT8/65/35 at room temperature. The coalescence of nanodomains and the formation of (110) wedge-shaped ferroelectric domains during the phase transition is consistent with our previous study on a $\mathrm{Pb}\left(\mathrm{Mg}_{1 / 3} \mathrm{Nb}_{2 / 3}\right) \mathrm{O}_{3}$-based relaxor composition $[44,45]$. Formation of large wedge-shaped ferroelectric domains is accompanied by a significant intensification of the $1 / 2\{000\}$ superlattice reflection spots [Fig. 6 (f)], which is highlighted in Fig. 6 (g) where the same $(\overline{22} 2)$ and $1 / 2(\overline{33} 3)$ spots are provided again. Note that the $(\overline{22} 2)$ fundamental diffraction spot is evidently distorted along the direction that is normal to the (110) domain walls, appearing as two split spots. The bright-field image of the grain after the applied field was removed for $1 \mathrm{~h}$ is presented in Fig. $6(\mathrm{~h})$. The preservation of the large ferroelectric domains confirms that the induced ferroelectric phase is sustained in the absence of an applied electric field and the relaxor-to-ferroelectric phase transition in PLZT8/65/35 is irreversible at room temperature.
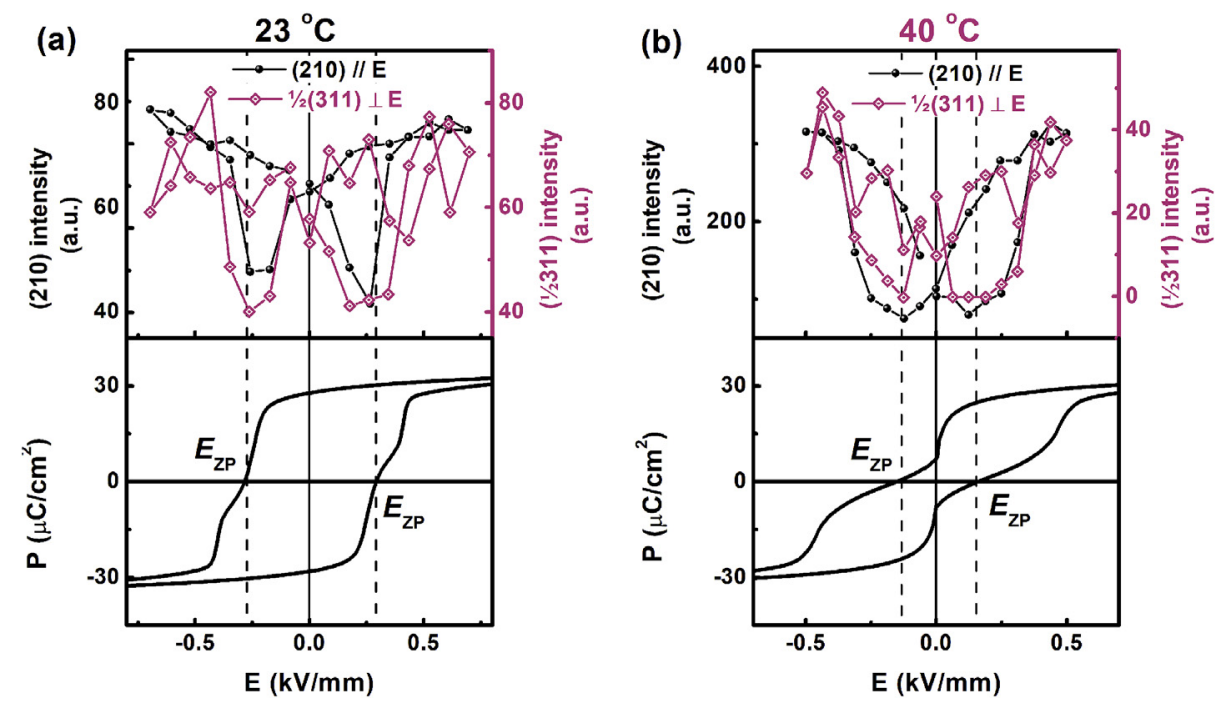

Fig. 5. The $1 / 2$ (311) and (210) peak intensity, and polarization hysteresis of PLZT at (b) $23^{\circ} \mathrm{C}$ and (c) $40^{\circ} \mathrm{C}$ as a function of applied electric field. 

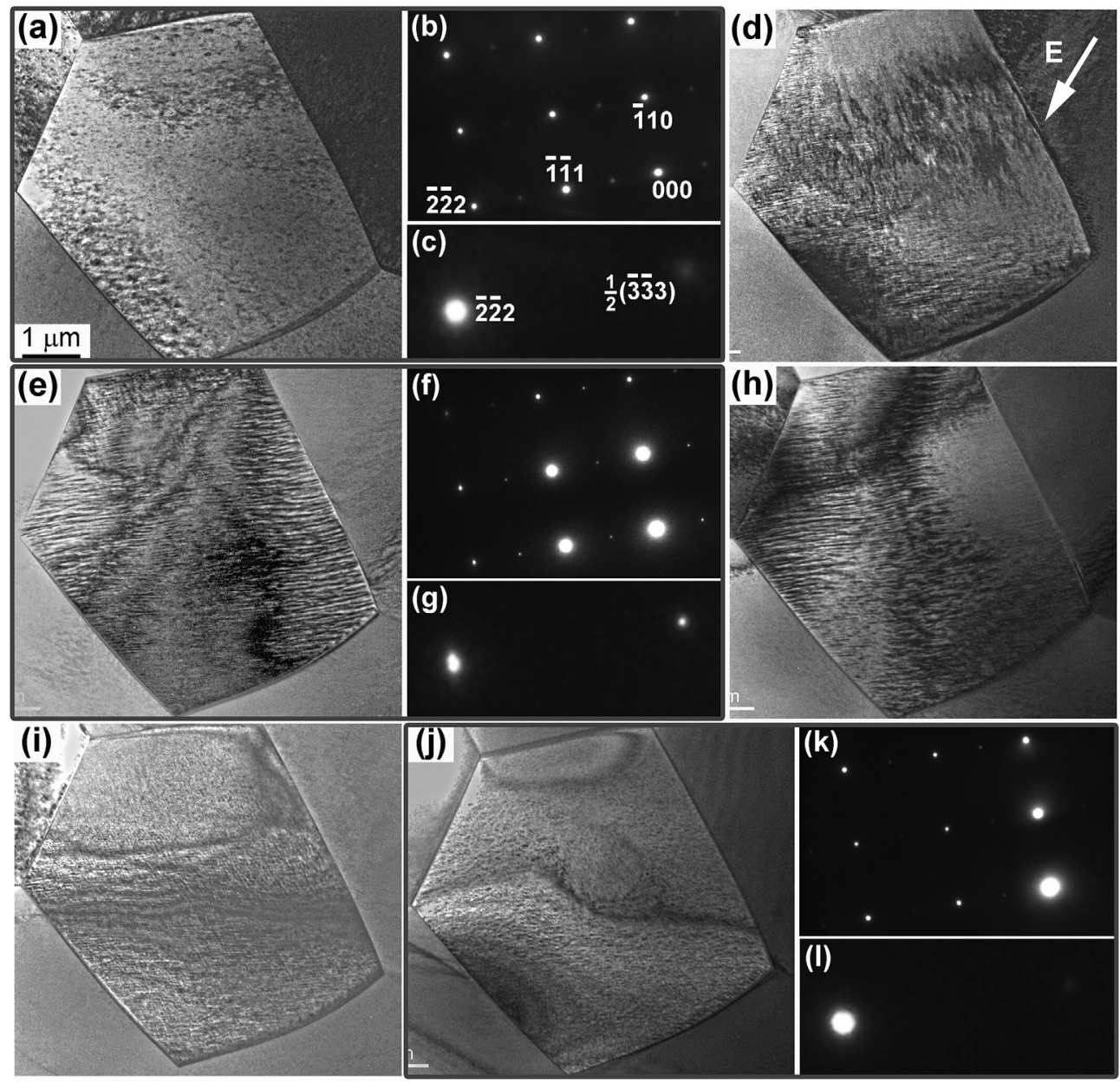

m)

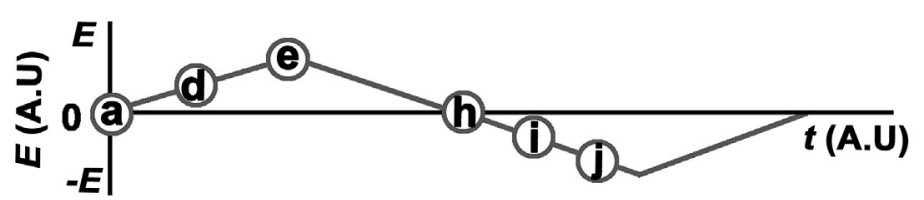

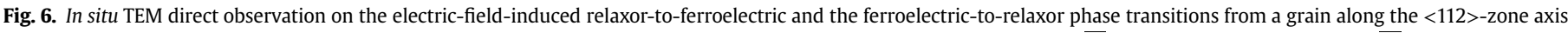

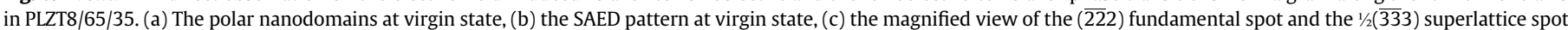

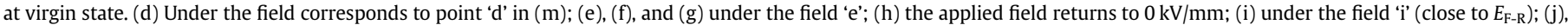

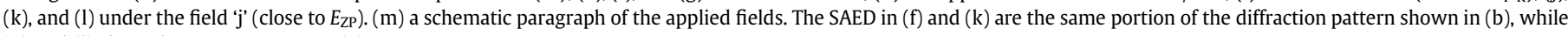
(g) and (l) show the same spots as in (c).

The in situ TEM experiment directly reveals that the polarization reversal takes place through a ferroelectric-to-relaxor phase transition. As displayed in Fig. 6 (i), when the field in the reverse polarity close to $E_{\mathrm{F}-\mathrm{R}}$ is applied, the large ferroelectric domains are disrupted into thin and short domains clustering in the same direction. In addition, nanodomains clustering along a different direction are also formed. At a field in the reverse direction corresponding to $E_{\mathrm{ZP}}$, almost the entire grain is occupied with relaxor nanodomains [Fig. 6 (j)]. At the same time, the SAED pattern similar to that formed at virgin state is seen with circularly shaped fundamental spots and extremely weak superlattice spots [Fig. $6(\mathrm{k})$ and (1)]. Further increase in the field magnitude in the reverse direction was observed to transform these nanodomains into large ferroelectric domains again, completing the polarization reversal process.

\subsection{Field dependence of $T_{d}$ and $T_{F-R}$}

The correlation between $T_{\mathrm{d}}-T_{\mathrm{F}-\mathrm{R}}$ and $E_{\mathrm{d}}-E_{\mathrm{F}-\mathrm{R}}$ for (a) PLZT and (b) BNT-6BT is outlined in Fig. 7. It is reasonable to assume that $T_{\mathrm{d}}$ and
$T_{\mathrm{F}-\mathrm{R}}$ should be defined at the point where $E_{\mathrm{d}}$ and $E_{\mathrm{F}-\mathrm{R}}$ (Fig. 1 ) become zero, respectively. The former and the latter coincide with the temperature, where the detexturization of ferroelectric domains $\left(T_{\mathrm{d}} / E_{\mathrm{d}}\right)$ and the miniaturization of detexurized ferroelectric domains $\left(T_{\mathrm{F}-\mathrm{R}} / E_{\mathrm{F}-\mathrm{R}}\right)$ take place, respectively. In this sense, we notice that $T_{\mathrm{d}}$ is located at the temperature near the onset point of thermally-stimulated depolarization instead of the inflection point, i.e., the peak of TSDC. The dielectric anomaly, which has commonly been taken as $T_{\mathrm{F}-\mathrm{R}}$, takes place slightly below the actual $T_{\mathrm{F}-\mathrm{R}}$.

\section{Conclusions}

A stepwise polarization reversal process via a ferroelectric to a relaxor state was observed in a nonergodic relaxor PLZT using in situ monitoring methods, namely, electrocalorimetry, neutron diffraction, and TEM measurements. A room-temperature electrocaloric analysis on the ceramic revealed that in addition to commonly expected electrocaloric heating peaks correlated with the development or reversal of domain texture, there existed an 

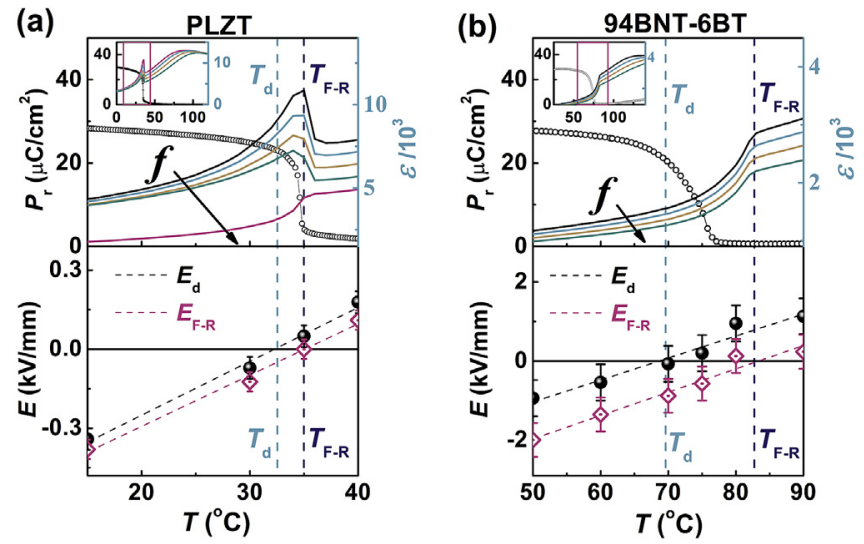

Fig. 7. Changes in the remanent polarization and the dielectric permittivity of electricfield-induced ferroelectric phase in (a) PLZT and (b) 94BNT-6BT with increasing temperature in comparison with $T_{\mathrm{d}}$ and $T_{\mathrm{F}-\mathrm{R}}$ extracted from temperature-dependent polarization hysteresis loops (bottom). Error bars were determined by the standard error of intercept of the linear polynomial fit.

extra cooling peak in-between two heating ones. In situ neutron diffraction study revealed that the extra cooling peak correlated with the vanishing of the electric-field-induced $1 / 2(000)$ superlattice reflections, which implies that there exists an intermediate process breaking down the electric-field-induced long-range order during polarization reversal. In situ TEM study further demonstrated that the initial unpoled state consisted of polar nanodomains, which coalesced into well-developed ferroelectric domains by the application of electric field; under reverse fields, the electric-fieldinduced ferroelectric domains were disrupted into polar nanodomains similar to those in the initial state. The current study suggests that $T_{\mathrm{d}}$ and $T_{\mathrm{F}-\mathrm{R}}$ do not have to be identical. A comparative study of both temperature-dependent and electrically-induced phase transitions verified that the deviation between $T_{\mathrm{d}}$ and $T_{\mathrm{F}-\mathrm{R}}$ is quantified by the gap between the depoling electric field $\left(E_{\mathrm{d}}\right)$ and a phase transition electric field $\left(E_{\mathrm{F}-\mathrm{R}}\right)$.

\section{Acknowledgements}

WJ is thankful for the financial support by the Basic Science Research Program through the National Research Foundation of Korea (NRF) funded by the Ministry of Education (NRF2018R1D1A1B07051176). XT acknowledges the financial support by the National Science Foundation (NSF) through Grant DMR1700014, and JD thanks the financial support from the ARC Discovery Project Scheme. We all acknowledge the support of the Australian Centre for Neutron Scattering, Australian Nuclear Science and Technology Organisation in providing the neutron research facilities used in this work.

\section{References}

[1] Haertling GH. Ferroelectric ceramics: history and technology. J Am Ceram Soc 1999;82(4):797-818.

[2] Hlinka J. Do we need the ether of polar nanoregions? J Adv Dielectr 2012;02(02):1241006

[3] Kleemann W. Random fields in relaxor ferroelectrics - a jubilee review. J Adv Dielectr 2012:02(02):1241001.

[4] Viehland D, Li JF, Jang SJ, Cross LE, Wuttig M. Dipolar-glass model for lead magnesium niobate. Phys Rev B 1991;43(10):8316-20.

[5] Viehland D, Jang SJ, Cross LE, Wuttig M. Freezing of the polarization fluctuations in lead magnesium niobate relaxors. J Appl Phys 1990;68(6):2916-21.

[6] Ke S, Fan H, Huang H. Revisit of the Vögel-Fulcher freezing in lead magnesium niobate relaxors. Appl Phys Lett 2010;97(13):132905.

[7] Pirc R, Kutnjak Z. Freezing in relaxor ferroelectrics and dipolar glasses. Phase Transitions 2015;88(3):222-33.

[8] Tagantsev AK. Vogel-Fulcher relationship for the dielectric permittivity of relaxor ferroelectrics. Phys Rev Lett 1994;72(7):1100-3.
[9] Bobnar V, Kutnjak Z, Pirc R, Levstik A. Electric-field-temperature phase diagram of the relaxor ferroelectric lanthanum-modified lead zirconate titanate. Phys Rev B: Condens Matter 1999;60(9):6420-7.

[10] Bobnar V, Kutnjak Z, Pirc R, Levstik A. Relaxor freezing and electricfield-induced ferroelectric transition in a lanthanum lead zirconate titanate ceramics. EPL (Europhys Lett) 1999;48(3):326.

[11] Anton E-M, Jo W, Damjanovic D, Rödel J. Determination of depolarization temperature of $\left(\mathrm{Bi}_{1 / 2} \mathrm{Na}_{1 / 2}\right) \mathrm{TiO}_{3}$-based lead-free piezoceramics. J Appl Phys 2011;110(9):094108.

[12] Zhao J, Zhang N, Ren W, Niu G, Walker D, Thomas Pamela A, Wang L, Ye Z-G. Polar domain structural evolution under electric field and temperature in the $\left(\mathrm{Bi}_{0.5} \mathrm{Na}_{0.5}\right) \mathrm{TiO}_{3}-0.06 \mathrm{BaTiO}_{3}$ piezoceramics. J Am Ceram Soc 2019;102(1): 437-47.

[13] Jo W, Dittmer R, Acosta M, Zang J, Groh C, Sapper E, Wang K, Rödel J. Giant electric-field-induced strains in lead-free ceramics for actuator applications status and perspective. J Electroceram 2012;29(1):71-93.

[14] Ke SM, Huang HT, Fan HO, Lee HK, Zhou LM, Mai Y-W. Antiferroelectric-like properties and enhanced polarization of Cu-doped $\mathrm{K}_{0.5} \mathrm{Na}_{0.5} \mathrm{NbO}_{3}$ piezoelectric ceramics. Appl Phys Lett 2012;101(8):082901.

[15] Shi J, Fan H, Liu X, Li Q. Giant strain response and structure evolution in $\left(\mathrm{Bi}_{0.5} \mathrm{Na}_{0.5}\right)_{0.945-x}\left(\mathrm{Bi}_{0.2} \mathrm{Sr}_{0.7} \square 0.1\right)_{x} \mathrm{Ba}_{0.055} \mathrm{TiO}_{3}$ ceramics. J Eur Ceram Soc 2014;34(15):3675-83.

[16] Carl K, Hardtl KH. Electrical after-effects in $\mathrm{Pb}(\mathrm{Ti}, \mathrm{Zr}) \mathrm{O}_{3}$ ceramics. Ferroelectrics 1977;17(1):473-86

[17] Granzow T, Suvaci E, Kungl H, Hoffmann MJ. Deaging of heat-treated irondoped lead zirconate titanate ceramics. Appl Phys Lett 2006;89(26):262908.

[18] Hong C-H, Kim H-P, Choi B-Y, Han H-S, Son JS, Ahn CW, Jo W. Lead-free piezoceramics - where to move on? J Materiomics 2016;2(1):1-24.

[19] Jo W, Daniels J, Damjanovic D, Kleemann W, Rödel J. Two-stage processes of electrically induced-ferroelectric to relaxor transition in $0.94\left(\mathrm{Bi}_{1 / 2} \mathrm{Na}_{1 / 2}\right) \mathrm{TiO}_{3}$ 0.06BaTiO. Appl Phys Lett 2013;102(19):192903.

[20] Calvarin G, Husson E, Ye ZG. X-ray study of the electric field-induced phase transition in single crystal $\mathrm{Pb}\left(\mathrm{Mg}_{1 / 3} \mathrm{Nb}_{2 / 3}\right) \mathrm{O}_{3}$. Ferroelectrics 1995;165(1): 349-58.

[21] Ye Z-G, Schmid H. Optical, dielectric and polarization studies of the electric field-induced phase transition in $\mathrm{Pb}\left(\mathrm{Mg}_{1 / 3} \mathrm{Nb}_{2 / 3}\right) \mathrm{O}_{3}$ [PMN]. Ferroelectrics 1993;145(1):83-108.

[22] Cheng ZY, Katiyar RS, Yao X, Guo A. Dielectric behavior of lead magnesium niobate relaxors. Phys Rev B 1997;55(13):8165-74.

[23] Farhi R, Marssi ME, Dellis JL, Picot JC, Morell A. On the nature of the glassy state in 9/65/35 PLZT ceramics. Ferroelectrics 1996;176(1):99-106.

[24] Schaab S, Granzow T. Temperature dependent switching mechanism of $\left(\mathrm{Pb}_{0.92} \mathrm{La}_{0.08}\right)\left(\mathrm{Zr}_{0.65} \mathrm{Ti}_{0.35}\right) \mathrm{O}_{3}$ investigated by small and large signal measurements. Appl Phys Lett 2010;97(13):132902.

[25] Sapper E, Schaab S, Jo W, Granzow T, Rödel J. Influence of electric fields on the depolarization temperature of Mn-doped (1- $x) \mathrm{Bi}_{1 / 2} \mathrm{Na}_{1 / 2} \mathrm{TiO}_{3}-x \mathrm{BaTiO}_{3}$. J Appl Phys 2012;111(1):014105.

[26] Bai W, Chen D, Zheng P, Shen B, Zhai J, Ji Z. Composition- and temperaturedriven phase transition characteristics and associated electromechanical properties in $\mathrm{Bi}_{0.5} \mathrm{Na}_{0.5} \mathrm{TiO}_{3}$-based lead-free ceramics. Dalton Trans 2016;45(20):8573-86.

[27] Daniels JE, Cozzan C, Ukritnukun S, Tutuncu G, Andrieux J, Glaum J, Dosch C, Jo W, Jones JL. Two-step polarization reversal in biased ferroelectrics. J Appl Phys 2014;115(22):224104.

[28] Genenko YA, Khachaturyan R, Schultheiß J, Ossipov A, Daniels JE, Koruza J. Stochastic multistep polarization switching in ferroelectrics. Phys Rev B 2018;97(14):144101.

[29] Glaum J, Simons H, Hudspeth J, Acosta M, Daniels JE. Temperature dependent polarization reversal mechanism in $0.94\left(\mathrm{Bi}_{1 / 2} \mathrm{Na}_{1 / 2}\right) \mathrm{TiO}_{3}-0.06 \mathrm{Ba}\left(\mathrm{Zr}_{0.02} \mathrm{Ti}_{0.98}\right) \mathrm{O}_{3}$ relaxor ceramics. Appl Phys Lett 2015;107(23):232906.

[30] Hong C-H, Fan Z, Tan X, Kang W-S, Ahn CW, Shin Y, Jo W. Role of sodium deficiency on the relaxor properties of $\mathrm{Bi}_{1 / 2} \mathrm{Na}_{1 / 2} \mathrm{TiO}_{3}-\mathrm{BaTiO}_{3}$. J Eur Ceram Soc 2018;38(16):5375-81.

[31] Simons H, Daniels JE, Studer AJ, Jones JL, Hoffman M. Measurement and analysis of field-induced crystallographic texture using curved positionsensitive diffraction detectors. J Electroceram 2014:32(4):283-91.

[32] Tan X, Xu Z, Shang JK, Han P. Direct observations of electric field-induced domain boundary cracking in $\langle 001\rangle$ oriented piezoelectric $\mathrm{Pb}\left(\mathrm{Mg}_{1 / 3} \mathrm{Nb}_{2 / 3}\right)$ $\mathrm{O}_{3}-\mathrm{PbTiO}_{3}$ single crystal. Appl Phys Lett 2000;77(10):1529-31.

[33] Tan X, Shang JK. In-situ transmission electron microscopy study of electricfield-induced grain-boundary cracking in lead zirconate titanate. Philos Mag A 2002;82(8):1463-78.

[34] Tan X, He H, Shang J-K. In situ transmission electron microscopy studies of electric-field-induced phenomena in ferroelectrics. J Mater Res 2005;20(7): $1641-53$.

[35] Daniels JE, Jo W, Rödel J, Honkimäki V, Jones JL. Electric-field-induced phasechange behavior in $\left(\mathrm{Bi}_{0.5} \mathrm{Na}_{0.5}\right) \mathrm{TiO}_{3}-\mathrm{BaTiO}_{3}-\left(\mathrm{K}_{0.5} \mathrm{Na}_{0.5}\right) \mathrm{NbO}_{3}$ : a combinatorial investigation. Acta Mater 2010;58(6):2103-11.

[36] Kutnjak Z, Rožič B, Pirc R. Electrocaloric effect: theory, measurements, and applications. Wiley Encyclopedia of Electrical and Electronics Engineering, John Wiley \& Sons, Inc; 2015.

[37] Scott JF. Electrocaloric materials. Annu Rev Mater Res 2011;41(1):229-40.

[38] Moya X, Defay E, Heine V, Mathur ND. Too cool to work. Nat Phys 2015;11(3): $202-5$.

[39] Ahn CW, Hong C-H, Choi B-Y, Kim H-P, Han H-S, Hwang Y, Jo W, Wang K, Li J- 
F, Lee J-S, Kim IW. A brief review on relaxor ferroelectrics and selected issues in lead-free relaxors. J Korean Phys Soc 2016;68(12):1481-94.

[40] Bokov AA, Ye ZG. Recent progress in relaxor ferroelectrics with perovskite structure. J Mater Sci 2006;41(1):31-52.

[41] Cross LE. Relaxor ferroelectrics, piezoelectricity. Springer Berlin Heidelberg; 2008. p. 131-55.

[42] Schmidt G, Arndt H, Borchhardt G, von Cieminski J, Petzsche T, Borman K, Sternberg A, Zirnite A, Isupov VA. Induced phase transitions in ferroelectrics with diffuse phase transition. Phys Status Solidi A 1981;63(2):501-10.

[43] Kamba S, Bovtun V, Petzelt J, Rychetsky I, Mizaras R, Brilingas A, Banys J, Grigas J, Kosec M. Dielectric dispersion of the relaxor PLZT ceramics in the frequency range 20 Hz-100 THz. J Phys: Condens Matter 2000;12(4):497.

[44] Qu W, Zhao X, Tan X. In situ transmission electron microscopy study of the nanodomain growth in a Sc-doped lead magnesium niobate ceramic. Appl Phys Lett 2006;89(2):022904.

[45] Qu W, Zhao X. Tan X. Evolution of nanodomains during the electric-fieldinduced relaxor to normal ferroelectric phase transition in a Sc-doped $\mathrm{Pb}\left(\mathrm{Mg}_{1 / 3} \mathrm{Nb}_{2 / 3}\right) \mathrm{O}_{3}$ ceramic. J Appl Phys 2007;102(8):084101.

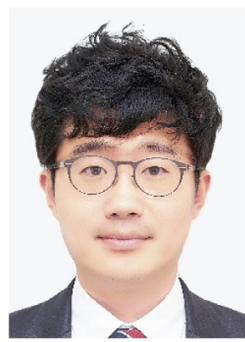

Chang-Hyo Hong is a postdoctoral research associate at Prof. Wook Jo's group in Ulsan National Institute of Science and Technology (UNIST), South Korea. He received his Ph.D. from UNIST in 2018. His graduate research focused on the chemically- and electrically-induced phase transitions of relaxor ferroelectrics. His research interests are mainly on fundamental analysis of relaxor ferroelectrics, lead-free piezoceramics, and their applications.

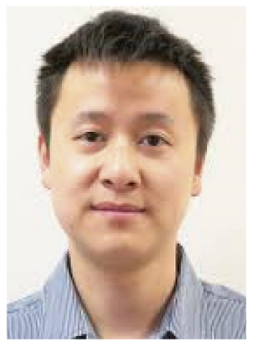

Hanzheng Guo is a senior development engineer at KEMET Electronics Corporation. He obtained his Ph.D. in Materials Science and Engineering from Iowa State University in 2014, focusing on in situ TEM study of the microstructural mechanisms for electric-field-induced phenomena in piezoelectrics and ferroelectrics. His current research interests focus on design-processing-structure-property relationships for ceramic-based materials.

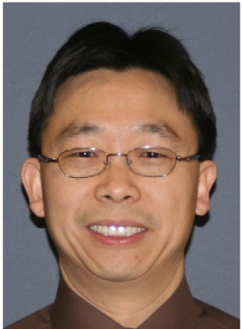

Xiaoli Tan is a professor of materials science and engineering at lowa State University of Science and Technology. He obtained his PhD degree from the University of Illinois at Urbana Champaign in 2002. He received an NSF CAREER Award in 2004. He is an associate editor of the Journal of the American Ceramic Society. His research focuses on the structure-property relationship in electroceramics, with in situ transmission electron microscopy as the primary characterization tool. He has published more than 130 articles.

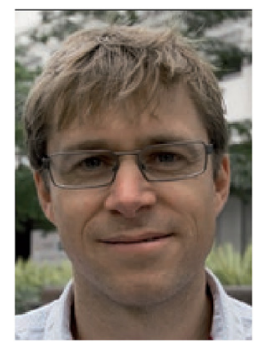

John E. Daniels is an associate professor in the School of Materials Science and Engineering at the University of New South Wales, Australia. He received his BS and $\mathrm{PhD}$ degrees in physics in 2003 and 2007, respectively, from Monash University, Australia. He completed postdoctoral research at The European Synchrotron, where he studied instrumentation and measurement methods for materials characterization. His research interests focus on structural measurement by scattering methods and electromechanical materials.

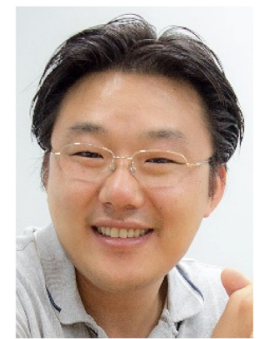

Wook Jo is a professor at the School of Materials Science and Engineering, Ulsan National Institute of Science and Technology (UNIST), South Korea. Prior to joining the faculty of UNIST in 2014, he had served as a group leader fo the Processing of Ferroelectrics Lab at the Institute of Materials Science, Technische Universität Darmstadt, Germany, since 2007. His recent research focuses on the functional properties of ferroelectric materials with specia emphasis on lead-free piezoceramics and relaxor ferroelectrics. He has published more than 140 papers, seven books, and holds six patents. 